\title{
Effects of Shrinkage Reducing Agent and Expansive Admixture on the Volume Deformation of Ultrahigh Performance Concrete
}

\author{
Su Anshuang, ${ }^{1}$ Qin Ling, ${ }^{2}$ Zhang Shoujie, ${ }^{1}$ Zhang Jiayang, ${ }^{1}$ and Li Zhaoyu ${ }^{1}$ \\ ${ }^{1}$ Heilongjiang Provincial Hydraulic Research Institute, Harbin 150080, China \\ ${ }^{2}$ School of Civil Engineering, Harbin Institute of Technology, Harbin 150090, China \\ Correspondence should be addressed to Su Anshuang; bridgecrete@163.com
}

Received 31 March 2017; Accepted 15 June 2017; Published 20 July 2017

Academic Editor: Xiao-Yong Wang

Copyright (c) $2017 \mathrm{Su}$ Anshuang et al. This is an open access article distributed under the Creative Commons Attribution License, which permits unrestricted use, distribution, and reproduction in any medium, provided the original work is properly cited.

\begin{abstract}
This paper investigated the influences of shrinkage reducing agent and expansive admixture on autogenous and drying shrinkage of ultrahigh performance concrete (UHPC) containing antifoaming admixture. The shrinkage reducing agent was used at dosage of $0.5 \%, 1 \%$, and $2 \%$ and the expansive admixture was used at dosage of $2 \%$ to $4 \%$ by mass of cementitious material. The results show that the air content of UHPC increases with the higher addition of shrinkage reducing agent and expansive admixtures. However, the fluidity, compressive strength, and shrinkage of UHPC exhibit a declining tendency. The usage of expansive agent at dosage of $4 \%$ significantly reduces the shrinkage of UHPC. The 7-day autogenous shrinkage was decreased by $16.0 \%$ and 28 -day drying shrinkage was decreased by $29.5 \%$, respectively. Shrinkage reducing agent at dosage of $2 \%$ reduced the 7 -day autogenous shrinkage by $44.3 \%$ and 28 -day drying shrinkage by $50.2 \%$. Compared with expansive admixture, shrinkage reducing agent exhibits more efficient shrinkage reduction effect on UHPC.
\end{abstract}

\section{Introduction}

As a new generation of concrete, ultrahigh performance concrete (UHPC) possesses numerous advantages such as high strength, high durability, high reliability, and high performance [1]. However, there is no unified standard about technical requirements for UHPC. In France, the guide "Ultrahigh Performance Fiber Reinforced Concrete-Interim Recommendations" described ultrahigh performance fiber reinforced concrete (UHPFRC) as a highly viscous cement based composite material with the 28-day compressive strength over $150 \mathrm{MPa}$, mixed with the steel fiber to increase toughness and mixed with fine quartz sand as aggregate [2]. And two French standards related to UHPFRC have been published in April 2016. Japanese Civil Engineering Society defined UHPC as a cement based material reinforced by steel fiber with 28-day compressive strength over $150 \mathrm{MPa}$ and mixed with cement and highly active volcanic ash as cementitious materials [3]. The diameter of aggregate was less than $2.5 \mathrm{~mm}$ and water-to-binder ratio was less than 0.24 . The content of steel fiber was less than $2 \%$ by volume of concrete. The diameter of steel fiber ranged from $0.10 \mathrm{~mm}$ to $0.25 \mathrm{~mm}$ and the length of steel fiber was in the range of $10 \mathrm{~mm}$ to $20 \mathrm{~mm}$. At present, the research and application of UHPC in China are still in the experimental stage and the accumulation of experimental data and engineering experience is very necessary.

Low water-to-binder ratio, high-efficiency water reducing agent, and highly active volcanic ash were applied in order to achieve the excellent performance of UHPC [4]. Nevertheless, the autogenous and drying shrinkage of UHPC also increased because of the application of the mentioned methods. The shrinkage of concrete would lead to the generation and propagation of internal microcracks, which could greatly decrease the durability of concrete, shorten its service life, and even cause serious engineering accidents [5]. Therefore, control of the shrinkage is crucial for the current research and application of UHPC [6].

Cwirzen et al. systematically studied the mechanical properties, volume stability, and durability of UHPC [7]. Experimental results showed that high curing temperature tended to improve the compressive strength of reactive powder concrete (RPC). The strength of the samples cured 
at high temperature could reach $200 \mathrm{MPa}$, while the highest compressive strength of the specimens cured at room temperature was only $150 \mathrm{MPa}$. The shrinkage of UHPC was high; furthermore, the shrinkage of the ultrahigh strength mortar (UHSM) was approximately twice as that of UHPC. However, UHPC and UHSM possessed excellent durability. Liu et al. investigated the influences of mineral powders on volume stability of RPC. The research results indicated that high content of mineral powders could decrease early-stage shrinkage value of RPC to $300 \times 10^{-6}$ and the development of shrinkage at later age was negligible [8]. Tam et al. investigated the influences of mixing proportions and curing conditions on the shrinkage of RPC [9]. The results showed that shrinkage increased with the decrease of water-tocement ratio and the increase of dosage of high-efficiency water reducing agents. However, the steel fiber and hightemperature autoclave curing could reduce the shrinkage of RPC effectively. Wong et al. investigated the shrinkage of RPC cured at room temperature [10]. The results showed that $1-$ day shrinkage accounted for $77 \%$ of the 7 -day total shrinkage when curing temperature was $20^{\circ} \mathrm{C}$ and the relative humidity was $50 \%$. Moreover, the size of specimen also had certain influence on the shrinkage value. The shrinkage of large specimen was lower than that of small one. Han concluded that the fly ash and other mineral powders had significant effects on the early-age shrinkage of RPC. Shrinkage reducing admixture and expansive agent could effectively decrease the early-age shrinkage of RPC, while excessive expansive agent could significantly increase the plastic shrinkage [11].

Shrinkage had negative impacts on the durability of UHPC, which needed to be controlled [12]. The incorporation of shrinkage reducing admixture and expansive agent was the effective method to improve the volume stability of UHPC. The introduction of antifoaming admixture could efficiently reduce internal bubbles of UHPC and make the microstructure more dense [13]. What is more, the addition of antifoaming admixture could greatly improve the mechanical and durability properties of UHPC. For UHPC with the addition of antifoaming admixture, few studies focused on the influence of shrinkage reducing admixture and expansive agent on the volume stability. This paper investigated the effects of shrinkage reducing agent and expansive agent on the shrinkage of UHPC mixed with antifoaming admixture and proposed some suggestions for future research work.

\section{Raw Materials and Test Methods}

2.1. Raw Materials. The cement used was ordinary Portland cement with the strength grade of 52.5 complying with the Chinese National Standard GB175-2007. The particle size distribution of cement was shown in Figure 1. The specific surface area of silica fume (SF) was $21000 \mathrm{~m}^{2} \mathrm{~kg}^{-1}$ and the pozzolanic activity index was $104 \%$. Two types of silica sand (SS) with bulk density of $1.405 \mathrm{~g} / \mathrm{m}^{3}$ and $1.329 \mathrm{~g} / \mathrm{m}^{3}$, respectively, were used. According to the theory of high packing, the mass ratio of the coarse and fine silica sand was $3.9: 4.9$. A polycarboxylate-based superplasticizer (SP) from Harbin Qiang Shi Company was used. It has a water reducing efficiency greater than $30 \%$ and a solid content

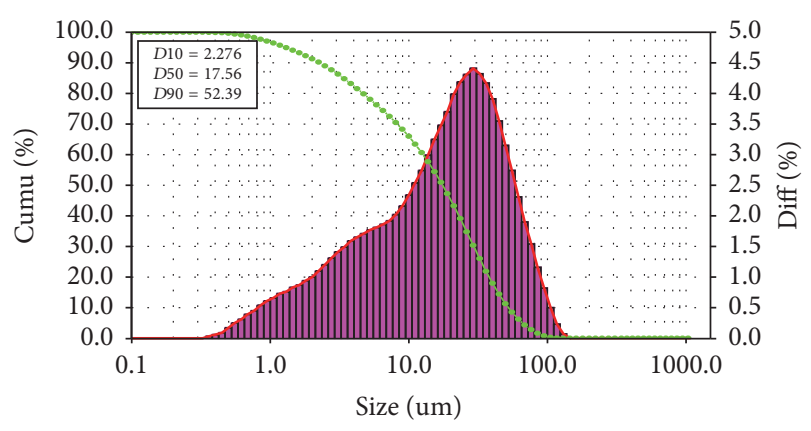

Figure 1: Particle size distribution of cement.

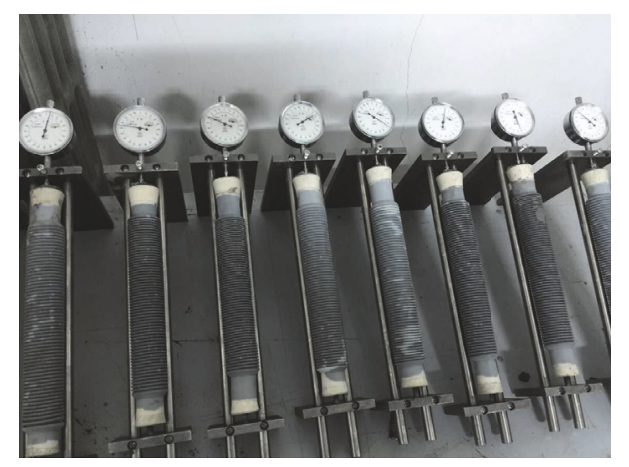

FIGURE 2: Autogenous shrinkage measuring device.

of about $40 \%$. The antifoaming admixture (AF) used was produced by Japanese Toho Chemical Industry Company. The shrinkage reducing agent (SRA) used was produced by Germany Evonik Industries. The expansive agent (EA) used was calcium magnesium compound expansive agent produced by Jiangsu Heitman Company Limited.

2.2. Test Methods. The mixing proportions of UHPC were shown in Table 1 . The water-to-binder ratio was 0.2 for all the mixtures.

The fluidity of UHPC was tested according to the Chinese standard GB/T 2419-2005. The mixture was cast into a minicone mold uniformly. The mini-slump cone has a base diameter of $60 \mathrm{~mm}$, a top diameter of $36 \mathrm{~mm}$, and a height of $60 \mathrm{~mm}$. Then the mold was lifted vertically and two diameters perpendicular to each other were measured. The mean value was recorded as slump flow to evaluate the fluidity. The air content was tested according to the Chinese standard GB/T 50080-2002. The mixture was cast into a cylinder container uniformly and the entrapped air content was recorded through a pressure gauge. The compressive strength was tested according to the Chinese standard GB/T 50081-2002.

Autogenous shrinkage of UHPC was tested by the selfdesigned measuring device shown in Figure 2. UHPC was mixed and cast into plastic corrugated pipe. After 6 hours, its initial length was measured. Then the dial gauge readings were recorded every 24 hours until the age of 7 days.

Drying shrinkage of UHPC was tested by the selfdesigned measuring device shown in Figure 3. UHPC was mixed and cast into the mold with the size of $25 \mathrm{~mm} \times$ 
TABLE 1: Mixing proportions of UHPC.

\begin{tabular}{lccccccc}
\hline Sample & Cement & SF & SS & Water & SP & AF & SRA \\
\hline JP0 & 100 & 25 & 110 & 25 & 1.8 & 0.5 & 0 \\
J1 & 100 & 25 & 110 & 25 & 1.8 & 0.5 & 0.5 \\
J2 & 100 & 25 & 110 & 25 & 1.8 & 0.5 & 1 \\
J3 & 100 & 25 & 110 & 25 & 1.8 & 0.5 & 0 \\
P1 & 100 & 25 & 110 & 25 & 1.8 & 0.5 & 0 \\
P2 & 100 & 25 & 110 & 25 & 1.8 & 0.5 & 0 \\
P3 & 100 & 25 & 110 & 25 & 1.8 & 0.5 & 0 \\
\hline
\end{tabular}

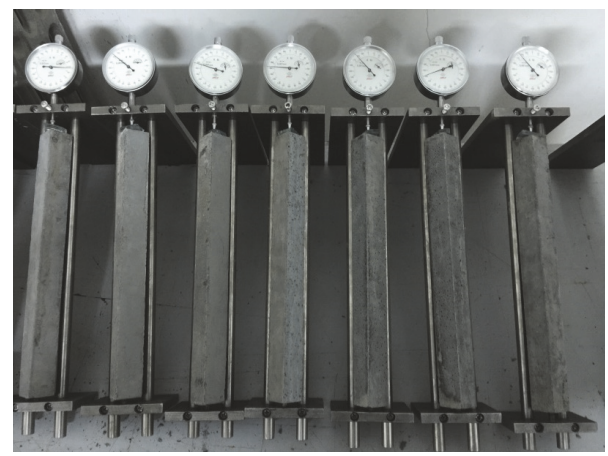

FIGURE 3: Drying shrinkage measuring device.

$25 \mathrm{~mm} \times 285 \mathrm{~mm}$. After curing under the temperature of $20 \pm 3^{\circ} \mathrm{C}$ and relative humidity beyond $90 \%$ for 2 days, the UHPC specimens were demolded and the initial length of the specimen was measured. Then the dial gauge readings were recorded every 24 hours until the age of 28 days.

The shrinkage of UHPC was calculated using the following equation:

$$
\varepsilon_{\mathrm{st}}=\frac{L_{0}-L_{t}}{L_{b}},
$$

where $\varepsilon_{\text {st }}$ was the shrinkage of UHPC, $L_{0}$ was the initial length of the specimen, measured value, $L_{t}$ is the measured value, $L_{b}$ was the standard length of the specimen.

\section{Results and Discussion}

3.1. Fluidity and Air Content. Figure 4 exhibited the effects of shrinkage reducing agent on the air content and fluidity of UHPC. It could be found that the fluidity of UHPC decreased with the increase of dosage of shrinkage reducing agent. It showed that the highest fluidity value reached $256 \mathrm{~mm}$ when UHPC was prepared without mixing the shrinkage reducing agent. But the fluidity of UHPC was decreased by $15.8 \%$ to $221 \mathrm{~mm}$ and by $24.2 \%$ to $201 \mathrm{~mm}$ when shrinkage reducing agent was used at the dosage of $0.5 \%$ and $2.0 \%$, respectively.

The incorporation of shrinkage reducing agent also had a significant effect on the air content of UHPC mortar. The air content of UHPC without the shrinkage reducing agent was $1.5 \%$. With the increase of the dosage of shrinkage reducing agent, the air content of UHPC showed sharp increase. The air content of UHPC was increased by $106.7 \%$ to $3.1 \%$ and by $180 \%$ to $4.2 \%$ when the shrinkage reducing agent was used at the dosage of $0.5 \%$ and $2.0 \%$, respectively. As mentioned

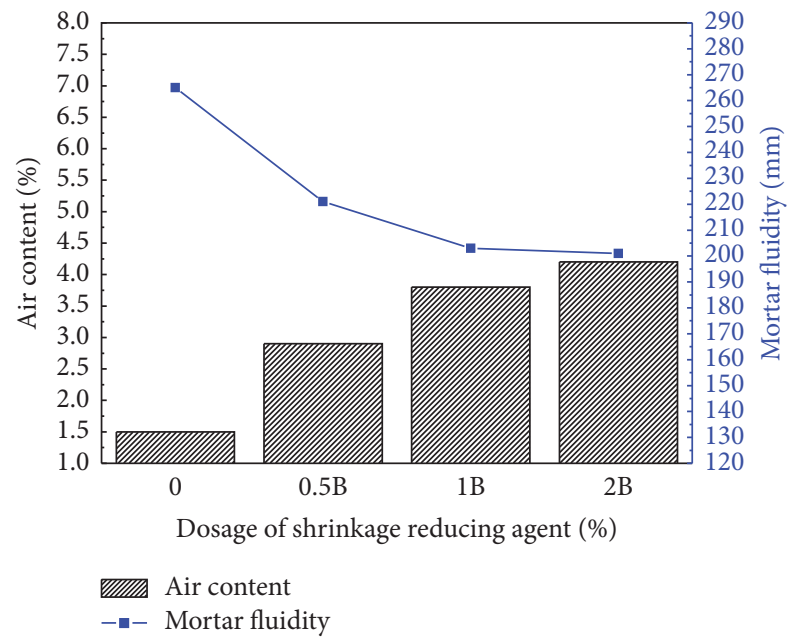

FIGURE 4: Effects of shrinkage reducing agent on air content and fluidity of UHPC.

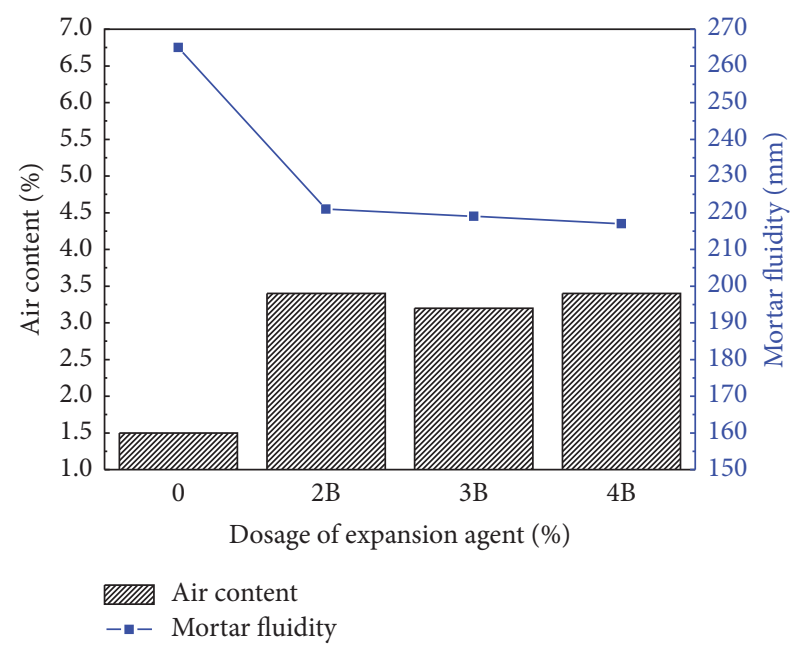

FIGURE 5: Effects of expansive agent on air content and fluidity of UHPC.

above, the fluidity of UHPC exhibited declining tendency with the introduction of the shrinkage reducing agent, which might hinder the release of the air in UHPC during the vibration procedure and resulted in the increase of the air content in UHPC.

Figure 5 showed the effects of expansive agent on the air content and fluidity of UHPC. The results indicated that the 


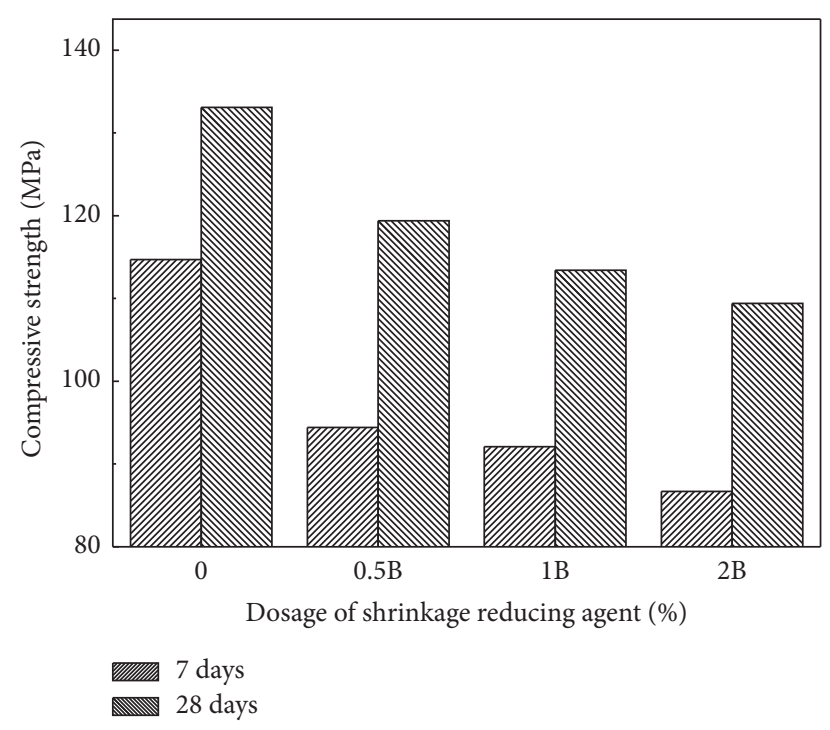

FIGURE 6: Effects of shrinkage reducing agent on compressive strength of UHPC.

fluidity decreased and air content increased obviously with the addition of expansive agent. Since the main chemical compositions of the expansive agent were $\mathrm{MgO}, \mathrm{CaO}$, and sulphoaluminate, much of mixing water was consumed due to the physical absorption and chemical reaction for UHPC with the introduction of expansive agent. The consumption of free water decreased the fluidity and hindered the release of air, which led to the increase of the air content. Some published research work also indicated that the addition of the expansive agent decreased the fluidity of concrete $[14,15]$.

3.2. Compressive Strength. Figure 6 showed the effects of shrinkage reducing agent on the compressive strength of UHPC. The results indicated that the compressive strength of UHPC decreased with the increase of dosage of shrinkage reducing agent. Some published studies also drew the same conclusion that the addition of shrinkage reducing agent decreased the compressive strength of mortar sample [1618]. For the samples without mixing with shrinkage reducing agent, 7-day and 28-day compressive strength reached 114.7 MPa and 133.1 MPa. However, when the shrinkage reducing agent was introduced at dosage of $2 \%$, 7-day and 28 -day compressive strength was decreased by $24.4 \%$ to $86.7 \mathrm{MPa}$ and by $17.8 \%$ to $109.4 \mathrm{MPa}$, respectively. The reduction caused by shrinkage reducing agent was more significant for the 7-day strength of UHPC, which indicated that shrinkage reducing agent had a more obvious effect on the early-age strength of UHPC.

Figure 7 exhibited the effects of expansive agent on the compressive strength of UHPC. The results showed that the compressive strength of UHPC decreased with the increase of dosage of expansive agent. The published research work obtained similar conclusion that the compressive strength of concrete decreased when the dosage of expansive agent exceeded $40 \mathrm{~kg} \cdot \mathrm{m}^{-3}[19]$.

For the samples without mixing with expansive agent, 7-day and 28-day compressive strength reached $114.7 \mathrm{MPa}$

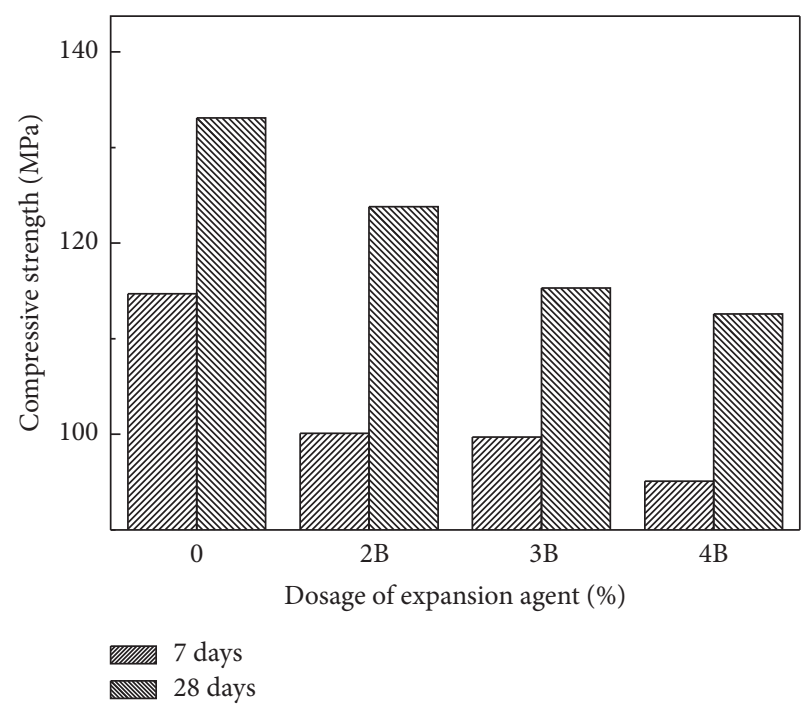

FIGURE 7: Effects of expansive agent on compressive strength of UHPC.

and $133.1 \mathrm{MPa}$. However, when the expansive agent was introduced at dosage of 2\%, 7-day and 28-day compressive strength was decreased by $12.7 \%$ to $100.1 \mathrm{MPa}$ and by $7.0 \%$ to 123.8 $\mathrm{MPa}$, respectively. The reduction caused by expansive agent was more significant for the 7-day strength of UHPC, which indicated that expansive agent had a more obvious effect on the early-age strength of UHPC.

3.3. Autogenous Shrinkage. Figure 8 exhibited the effects of shrinkage reducing agent on the autogenous shrinkage of UHPC. The results showed that the autogenous shrinkage of UHPC decreased with the introduction of shrinkage reducing agent. A published study obtained similar result that the use of shrinkage reducing agent was favorable for improving the restrained autogenous shrinkage behaviors of UHPFRC [20]. The autogenous shrinkage developed in the first 3 days was dominant and then the growth rate of shrinkage tended to be slow. For the sample without mixing with shrinkage reducing agent, 7-day autogenous shrinkage reached $1080 \times 10^{-6}$. However, 7-day autogenous shrinkage decreased to $718 \times 10^{-6}, 649 \times 10^{-6}$, and $602 \times 10^{-6}$ when the shrinkage reducing agent was used at dosage of $0.5 \%$, $1.0 \%$, and $2.0 \%$, respectively. That is to say, 7-day autogenous shrinkage of samples with shrinkage reducing agent at dosage of $0.5 \%, 1.0 \%$, and $2.0 \%$ was decreased by $33.5 \%, 39.9 \%$, and $44.3 \%$, respectively.

Figure 9 showed the effects of expansive agent on the autogenous shrinkage of UHPC. The results indicated that the autogenous shrinkage of UHPC decreased with the introduction of expansive agent. For the sample without mixing with expansive agent, 7-day autogenous shrinkage reached $1080 \times 10^{-6}$. However, 7-day autogenous shrinkage decreased to $907 \times 10^{-6}, 920 \times 10^{-6}$, and $937 \times 10^{-6}$ when the expansive agent was introduced at dosage of $4.0 \%, 3.0 \%$, and $2.0 \%$, respectively. That is to say, 7 -day autogenous shrinkage of samples with expansive agent at dosage of $4.0 \%, 3.0 \%$, and $2.0 \%$ was decreased by $16.0 \%, 15.2 \%$, and $13.2 \%$, respectively. 


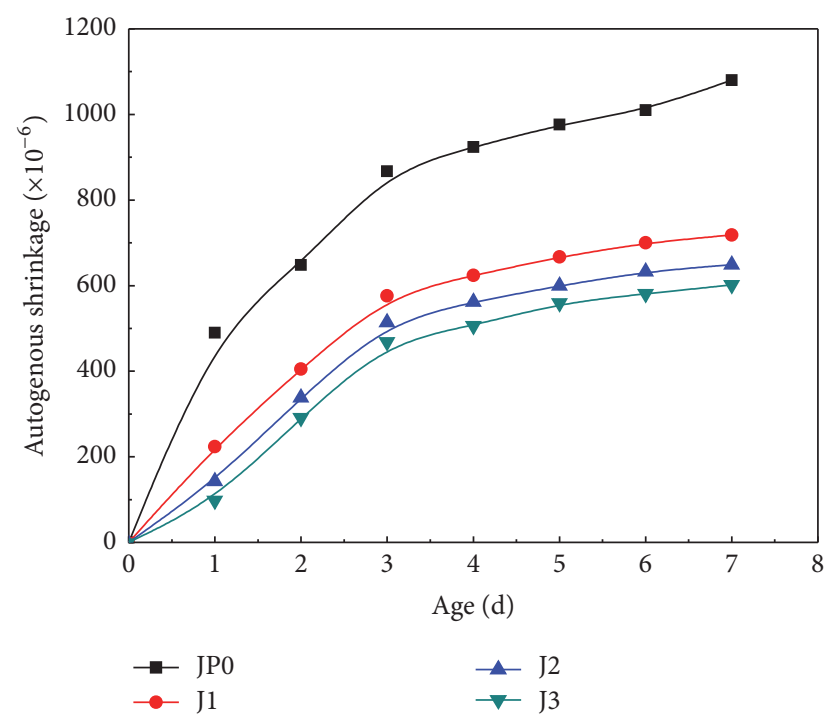

FIGURE 8: Effects of shrinkage reducing agent on autogenous shrinkage of UHPC.

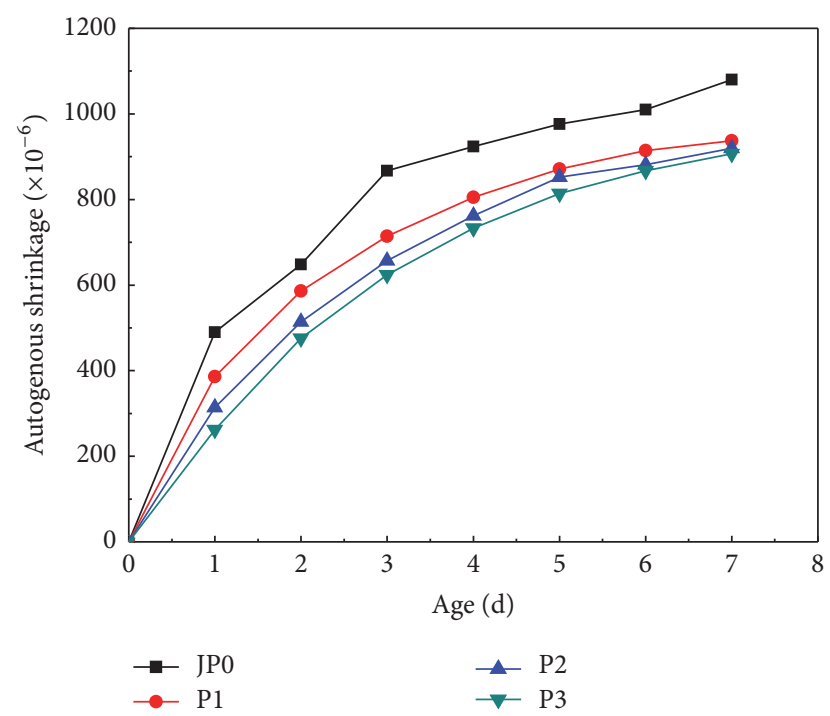

FIGURE 9: Effects of expansive agent on autogenous shrinkage of UHPC.

Compared with the results in Figure 8, shrinkage reducing agent had more significant shrinkage reducing effect than expansive agent for autogenous shrinkage of UHPC.

3.4. Drying Shrinkage. Figure 10 exhibited the effects of shrinkage reducing agent on the drying shrinkage of UHPC. The results showed that the drying shrinkage developed in the first five days was dominant and then the growth rate of shrinkage tended to be slow. The results also indicated that the variation of drying shrinkage after 10 days was relatively low. The 10-day drying shrinkage of samples JP0, J1, J2, and J3 was $719 \times 10^{-6}, 442 \times 10^{-6}, 404 \times 10^{-6}$, and $371 \times 10^{-6}$, which accounted for $87.2 \%, 96.9 \%, 92.9 \%$, and $90.3 \%$ of $28-$ day drying shrinkage, respectively.

It could also be found that the drying shrinkage of UHPC decreased obviously when the shrinkage reducing agent was

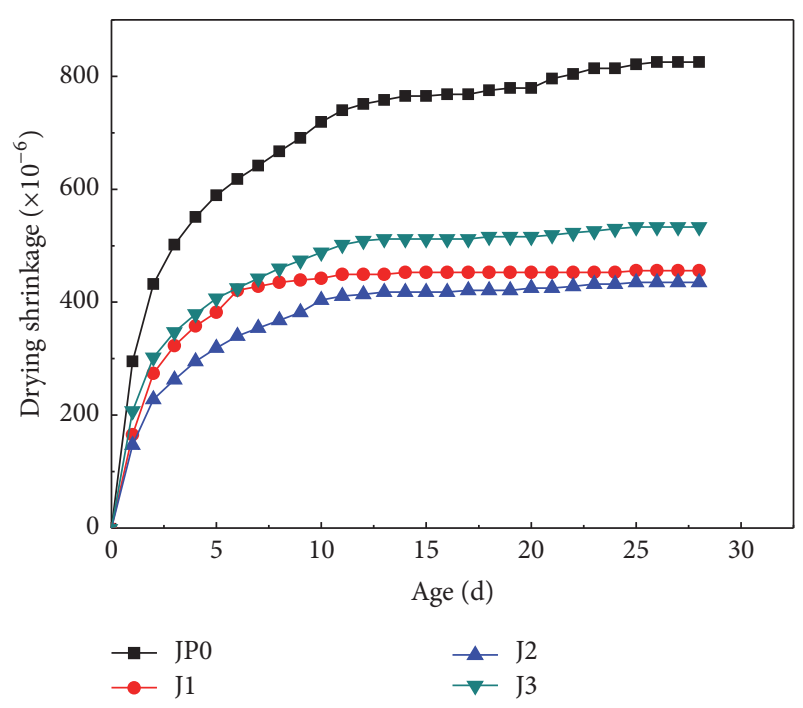

FIGURE 10: Effects of shrinkage reducing agent on drying shrinkage of UHPC.

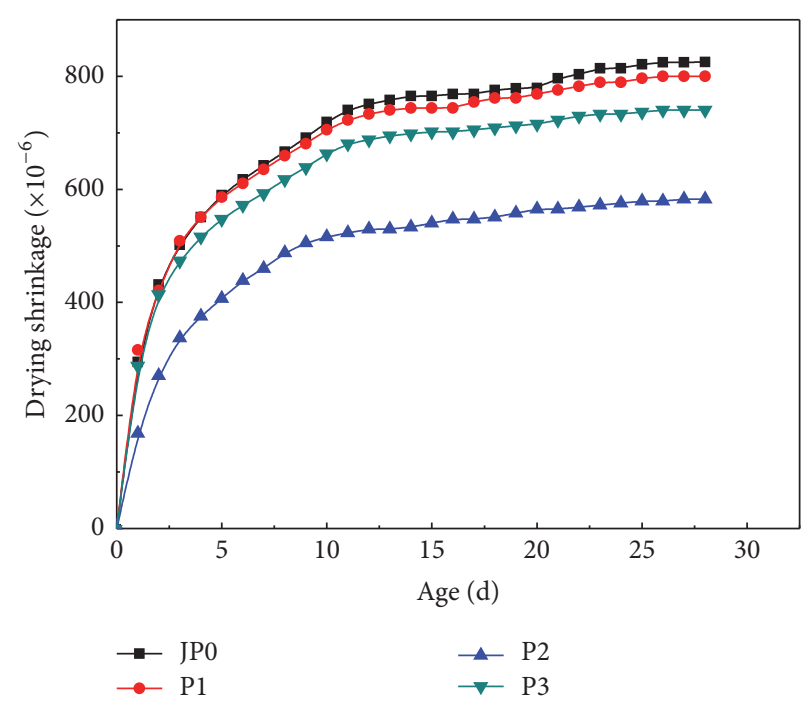

FIgURE 11: Effects of expansive agent on the drying shrinkage of UHPC.

introduced. A published research work obtained similar conclusion [21]. Shrinkage reducing agent was regarded as one of the important measures to prevent shrinkage cracking of concrete [22]. 28-day drying shrinkage decreased to 411 $\times 10^{-6}, 435 \times 10^{-6}$, and $456 \times 10^{-6}$ when the shrinkage reducing agent was introduced at dosage of $2.0 \%, 1.0 \%$, and $0.5 \%$, respectively. That is to say, 28 -day drying shrinkage of samples with shrinkage reducing agent at dosage of $2.0 \%$, $1.0 \%$, and $0.5 \%$ was decreased by $50.2 \%, 47.3 \%$, and $44.7 \%$, respectively. With the increase of the dosage, the shrinkage reducing agent exhibited more significant reducing effect for the drying shrinkage.

Figure 11 exhibited the effects of expansive agent on the drying shrinkage of UHPC. The results showed that the drying shrinkage of UHPC decreased with the introduction 
of expansive agent. It was also reported that expansive agent decreased the drying shrinkage of UHPC [15]. The main chemical compositions of expansive agent were $\mathrm{MgO}$, $\mathrm{CaO}$, and sulphoaluminate; the reaction mechanism of those crystals are as follows:

$$
\begin{aligned}
\mathrm{MgO}+\mathrm{H}_{2} \mathrm{O} & \longrightarrow \mathrm{Mg}(\mathrm{OH})_{2} \\
\mathrm{CaO}+\mathrm{H}_{2} \mathrm{O} & \longrightarrow \mathrm{Ca}(\mathrm{OH})_{2} \\
\mathrm{C}_{4} \mathrm{~A}_{3} \mathrm{~S}+\mathrm{H}_{2} \mathrm{O} & \longrightarrow \mathrm{AFt}
\end{aligned}
$$

The generation and growth of these crystals filled the pore and increased the density of UHPC, which could help in the expansion of cement paste and decrease the shrinkage of concrete. For the sample without mixing with expansive agent, 28 -day drying shrinkage reached $825 \times 10^{-6}$. However, 28-day drying shrinkage decreased to $582 \times 10^{-6}, 740 \times 10^{-6}$, and 800 $\times 10^{-6}$ when the expansive agent was introduced at dosage of $4.0 \%, 3.0 \%$, and $2.0 \%$, respectively. That is to say, 28 -day drying shrinkage of samples with expansive agent at dosage of $4.0 \%, 3.0 \%$, and $2.0 \%$ was decreased by $29.5 \%, 10.3 \%$, and $3.0 \%$, respectively. Compared with the results in Figure 10, shrinkage reducing agent had more significant reducing effect than expansive agent for drying shrinkage of UHPC.

\section{Conclusion}

From the above experimental results, the following conclusions can be obtained.

(1) The air content of UHPC increases with the increasing dosage of shrinkage reducing agent and expansive admixture and the fluidity of fresh UHPC shows a declining tendency.

(2) The higher addition of shrinkage reducing agent and expansive admixture results in the lower compressive strength of UHPC. This negative effect on compressive strength is more obvious at early ages.

(3) Both autogenous and drying shrinkage of UHPC decrease obviously with the higher dosage of shrinkage reducing agent and expansive admixture. Shrinkage reducing agent presents a more significant reduction effect on shrinkage of UHPC than expansive agent.

\section{Conflicts of Interest}

The authors declare that there are no conflicts of interest regarding the publication of this paper.

\section{Acknowledgments}

The support of Heilongjiang Provincial Major Scientific and Technological Project of Applied Technology Research and Development Plan (GA14A501) is acknowledged.

\section{References}

[1] F. de Larrard and T. Sedran, "Optimization of ultra-highperformance concrete by the use of a packing model," Cement and Concrete Research, vol. 24, no. 6, pp. 997-1009, 1994.
[2] Association Francaise de Genie Civil, UltRa High Performance Fiber-Reinforced Concretes-Interim Recommendations, Association Francaise de Genie Civil, Paris, France, 2002.

[3] Japan Society of Civil Engineers, Recommendations forfbfbDesignfbfbandfbfbConstruction of Ultra High Strength Fiber Reinforced Concrete Structures (DRAFT), Japan Society of Civil Engineers, Tokyo, Japan, 2006.

[4] P. Richard and M. Cheyrezy, "Composition of reactive powder concretes," Cement and Concrete Research, vol. 25, no. 7, pp. 1501-1511, 1995.

[5] E. Shaheen, N. G. Shrive, S. Allena, and C. M. Newtson, "Optimization of mechanical properties and durability of reactive powder concrete," ACI Materials Journal, vol. 104, no. 5, p. 547, 2007.

[6] S. Collepardi, L. Coppola, R. Troli et al., "Mechanisms of actions of different superplasticizers for high-performance concrete," in Proceedings of the International Conference on High Performance Concrete \& Performance \& Quality of Concrete Structures, 1999.

[7] A. Cwirzen, V. Penttala, and C. Vornanen, "Reactive powder based concretes: mechanical properties, durability and hybrid use with OPC," Cement and Concrete Research, vol. 38, no. 10, pp. 1217-1226, 2008.

[8] J. H. Liu, D. M. Wang, and S. M. Song, "Research on durability and micro structure of high volume fine mineral mixture of reactive powder concrete," Journal of Wuhan University of Technology, vol. 30, no. 11, pp. 54-55, 2008.

[9] C. M. Tam, V. W. Y. Tam, and K. M. Ng, "Assessing drying shrinkage and water permeability of reactive powder concrete produced in Hong Kong," Construction and Building Materials, vol. 26, no. 1, pp. 79-89, 2012.

[10] A. C. L. Wong, P. A. Childs, R. Berndt, T. Macken, G. Peng, and N. Gowripalan, "Simultaneous measurement of shrinkage and temperature of reactive powder concrete at early-age using fibre Bragg grating sensors," Cement and Concrete Composites, vol. 29, no. 6, pp. 490-497, 2007.

[11] S. Han, Y. Tu, M. An et al., "The shrinkage of reactive powder concrete in early age and its control methods," China Railway Science, vol. 36, no. 1, pp. 40-47, 2015 (Chinese).

[12] D.-Y. Yoo, J.-J. Park, S.-W. Kim, and Y.-S. Yoon, "Early age setting, shrinkage and tensile characteristics of ultra high performance fiber reinforced concrete," Construction and Building Materials, vol. 41, pp. 427-438, 2013.

[13] H. Yazic1, "The effect of curing conditions on compressive strength of ultra high strength concrete with high volume mineral admixtures," Building and Environment, vol. 42, no. 5, pp. 2083-2089, 2007.

[14] B. You and N. Li, Expansive Agent and Its Compensation Shrinkage Concrete, China Building Industry Press, 2005.

[15] Z. Huang, Y. Liu, and C. Li, "Performance research of high performance concrete incorporating HCSA expansion agent," Materials Review, vol. 4, pp. 116-121, 2015 (Chinese).

[16] Z. He, Z. J. Li, M. Z. Chen, and W. Q. Liang, "Properties of shrinkage-reducing admixture-modified pastes and mortar," Materials and Structures, vol. 39, no. 4, pp. 445-453, 2006.

[17] C. Maltese, C. Pistolesi, A. Lolli, A. Bravo, T. Cerulli, and D. Salvioni, "Combined effect of expansive and shrinkage reducing admixtures to obtain stable and durable mortars," Cement and Concrete Research, vol. 35, no. 12, pp. 2244-2251, 2005.

[18] D. P. Bentz, "Influence of shrinkage-reducing admixtures on early-age properties of cement pastes," Journal of Advanced Concrete Technology, vol. 4, no. 3, pp. 423-429, 2006. 
[19] S. Zhao and B. You, The Crack Control Technology of Compensation Shrinkage Concrete and Its Application, China Building Industry Press, 2010.

[20] D.-Y. Yoo, N. Banthia, and Y.-S. Yoon, "Effectiveness of shrinkage-reducing admixture in reducing autogenous shrinkage stress of ultra-high-performance fiber-reinforced concrete," Cement and Concrete Composites, vol. 64, pp. 27-36, 2015.

[21] B. L. Cope and G. E. Ramey, "Reducing drying shrinkage of bridge deck concrete," Concrete International, vol. 23, no. 8, pp. 76-82.

[22] P. S. Shah, E. M. Karagular, and M. Sarigaphuti, "Effects of shrinkage reducing admixture on rest rained shrinkage cracking of concrete," ACI Materials Journal, vol. 89, no. 3, pp. 88-90, 1992. 

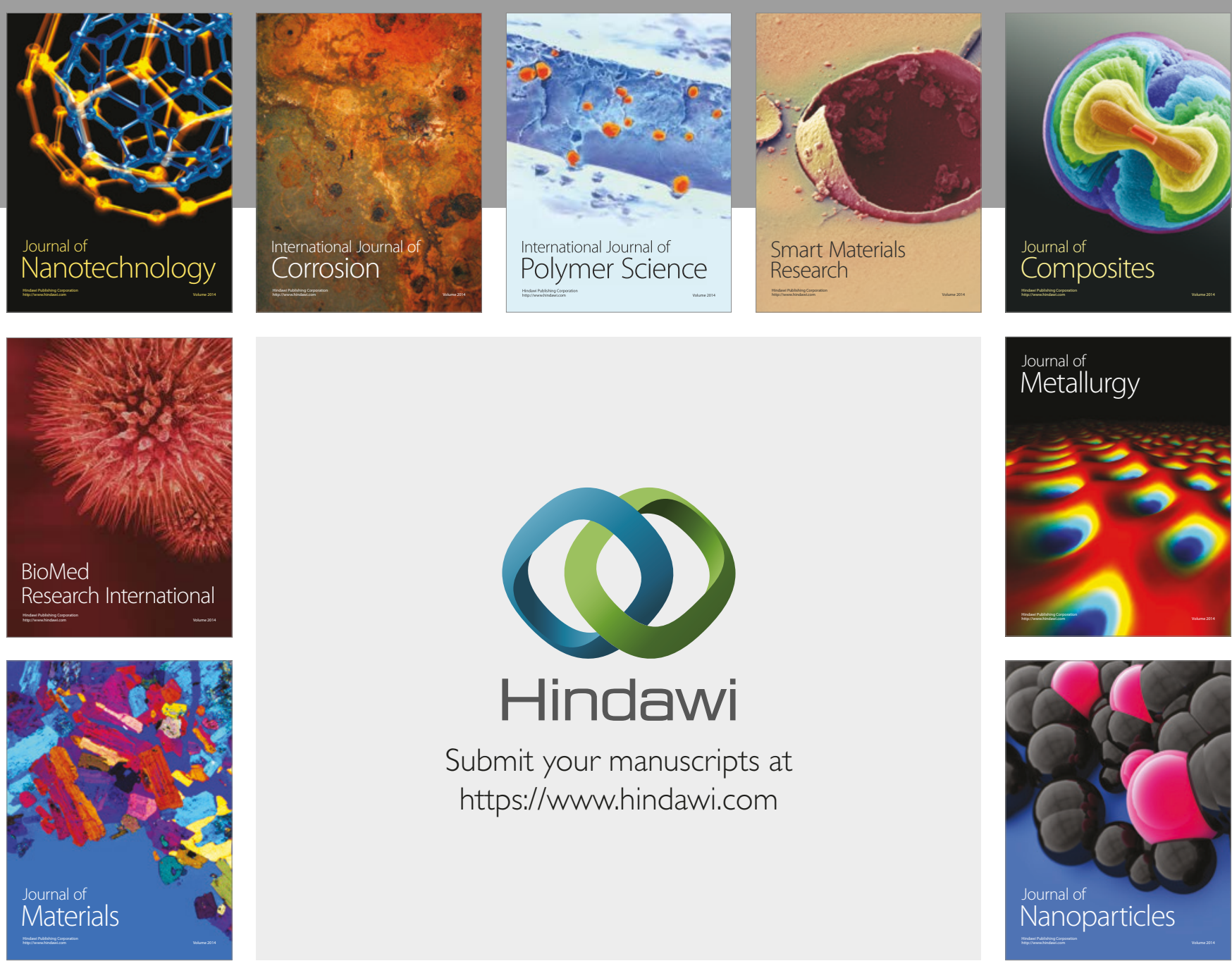

\section{Hindawi}

Submit your manuscripts at

https://www.hindawi.com
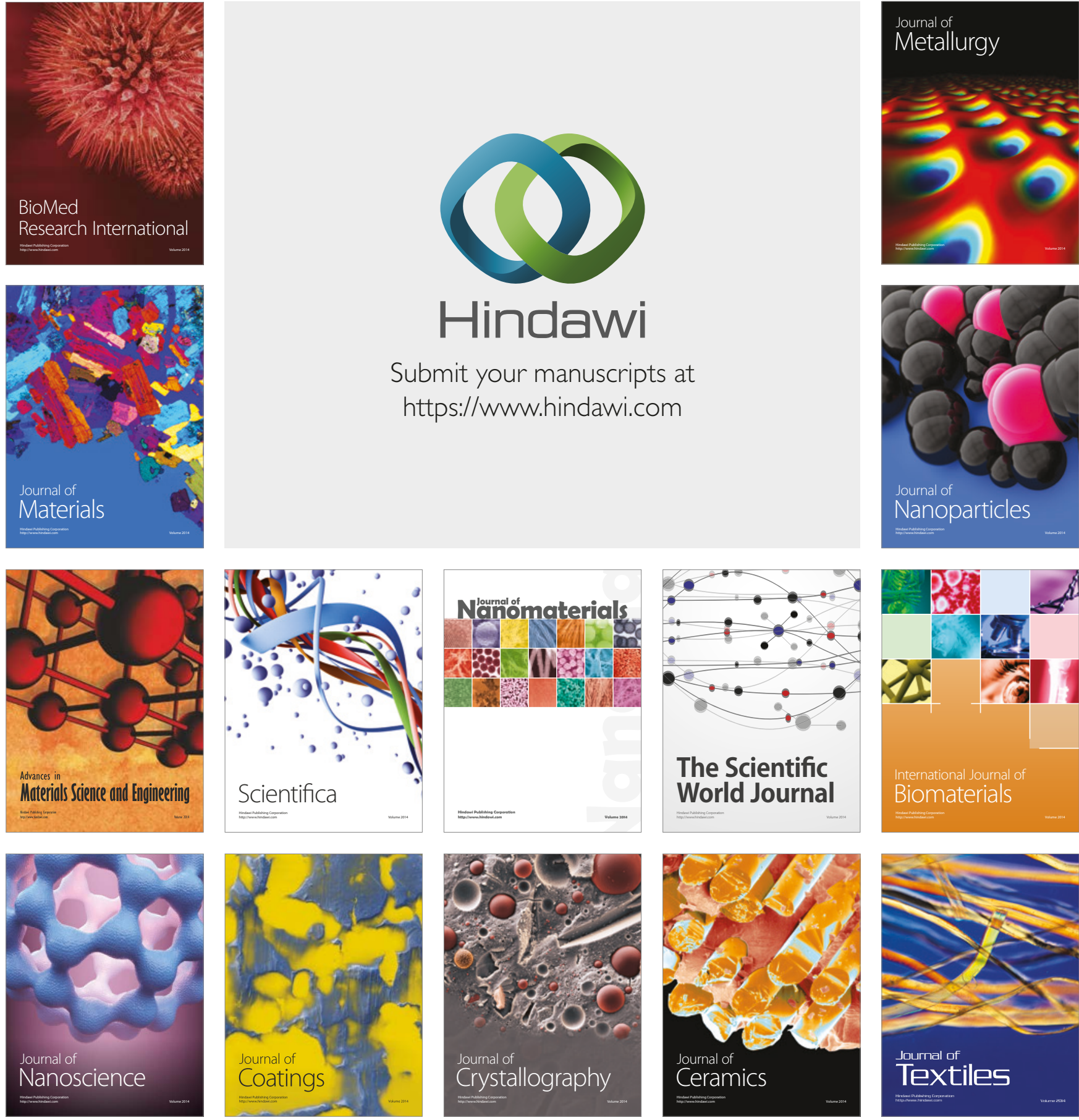

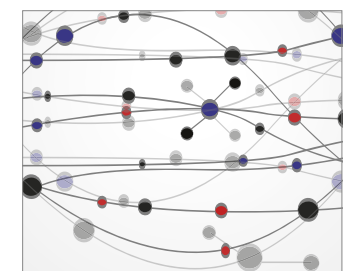

The Scientific World Journal
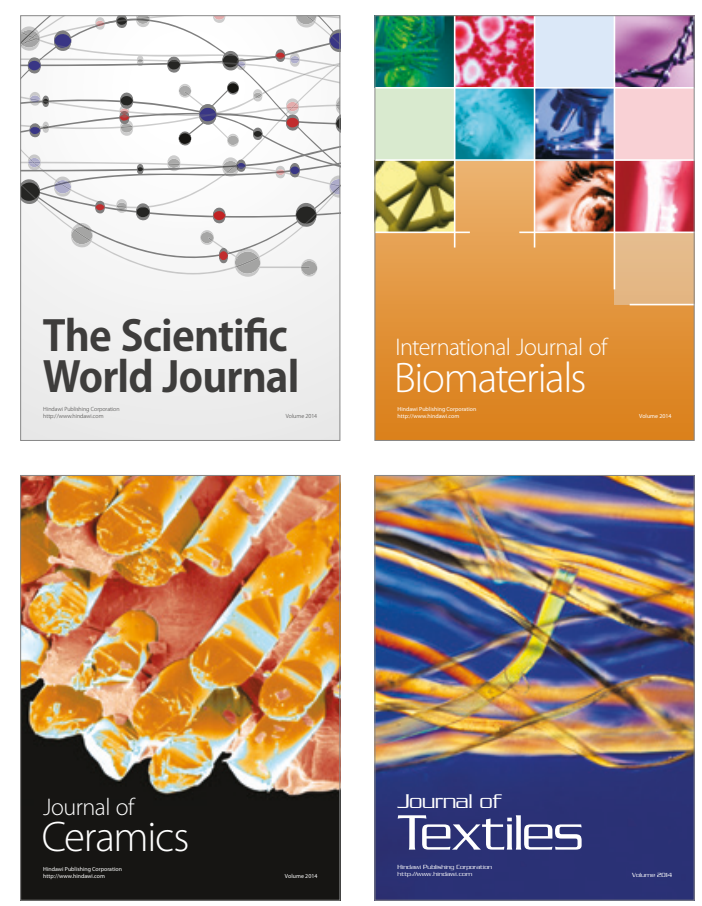